\title{
Non-infective colitis in infancy: evidence in favour of minor immunodeficiency in its pathogenesis
}

\author{
Ayodele Ojuawo, Deborah St Louis, Keith J Lindley, Peter J Milla
}

\begin{abstract}
Forty two infants below the age of 2 years presenting with chronic non-infective diarrhoea and shown to have histologically proved colitis were investigated over a five year period. Allergic colitis was the most common cause of colitis, accounting for $62 \%$ of the cases. Other colitides diagnosed included: non-specific colitis, autoimmune enterocolitis, and ulcerative colitis accounting for $10 \%$ each; severe combined immunodeficiency 7\%, and Crohn's disease $3 \%$. A positive family history and a personal history of atopy were obtained in $48 \%$ and $29 \%$ of the cases respectively. Serum immunoglobulin A, IgG ${ }_{2}$, and IgG $_{4}$ were very low in over $50 \%$ of the entire cohort of infants with colitis; $66 \%$ of those with severe combined immunodeficiency, autoimmune enterocolitis, and ulcerative colitis $(n=11)$ had low CD3 and CD4 T lymphocytes with an accompanying increase in CD8 in two thirds of those with severe combined immunodeficiency. $T$ lymphocytes were normal in those with allergic colitis. Thus infants with proved non-infective colitis as a group show a high prevalence of $\operatorname{IgA}_{1} \operatorname{IgG}_{2}$, and IgG $_{4}$ deficiency. It is likely that this minor deficiency of mucosa associated immunoglobulin production has a role in the pathogenesis of the colitic process.

(Arch Dis Child 1997;76:345-348)
\end{abstract}

Keywords: infants; rectal bleeding; colitis; serum immunoglobulin A; immunoglobulin $G$ subclasses

Colitis in infancy and early childhood comprises a heterogeneous group of conditions ${ }^{1}$; while infective colitides are the commonest overall, ${ }^{2-4}$ allergic colitis, ${ }^{56}$ and other specific and non-specific colitides are described. ${ }^{7}$ Food allergy is an important cause of noninfective colitis in the first two years of life. ${ }^{9-11}$

Gastroenterology Unit, Institute of Child Health, 30 Guilford Street, London WC1N $1 \mathrm{EH}$

A Ojuawo

D St Louis

K J Lindley

P J Milla

Correspondence to: Dr Lindley.

Accepted 4 November 1996
Ulcerative colitis and Crohn's disease are uncommon in this age group. ${ }^{12}$

There have been few studies of non-infective infantile colitis and none of immune function in these children.

In this study we discuss the clinical, group of infants presenting at less than 2 years of age who had histologically proved colitis. We pay particular attention to their immune function. pathological, and therapeutic findings in a

\begin{abstract}
Methods
PATIENTS

All children aged less than 2 years referred with recurrent non-infective bloody diarrhoea over the five year period January 1990 to December 1994 were recruited into the study.

All patients had clinical and endoscopic assessment and a histological diagnosis of colitis. The following investigations were routinely performed: full blood count and differential white cell count, serum albumin, serum immunoglobulins and immunoglobulin $G$ subclasses, nitroblue tetrazolium test, barium meal and follow through, technetium white cell scan, and intradermal skin prick test to an assortment of allergens. Stool cultures were negative for parasitic, bacterial, and viral isolates, and tests for Clostridium difficile toxin were negative in all cases.
\end{abstract}

\section{COLONOSCOPY}

Colonoscopy with multiple biopsies was performed in all patients using an Olympus PCF-20 colonoscope.

\section{HISTOLOGICAL DIAGNOSTIC CRITERIA}

Ulcerative colitis

Diffuse mucosal inflammatory cell infiltration, with crypt architectural distortion, loss of goblet cells, and Paneth cell metaplasia.

\section{Crohn's disease}

Evidence of transmural inflammation and focal inflammatory cell aggregation with noncaseating epithelioid granuloma formation.

\section{Allergic colitis}

Normal morphology with an increased inflammatory cell infiltrate, containing an increase in eosinophils which clump together, degranulate, and infiltrate the epithelium.

\section{Non-specific colitis}

Mixed chronic inflammatory cell infiltrate within the lamina propria with no specific features of ulcerative colitis or Crohn's disease.

\section{Autoimmune enterocolitis}

Chronic inflammation consisting almost entirely of plasma cells and lymphocytes with or without focal cryptitis in association with positive serological investigations (positive smooth muscle and gut autoantibodies).

\section{Results}

Over the period 1990 to 1994,42 infants who fulfilled the inclusion criteria of histologically proved non-infective colitis were investigated. 
Table 1 Clinical features of 42 infants at presentation with colitis

\begin{tabular}{|c|c|c|c|c|c|c|c|}
\hline \multirow[t]{2}{*}{ Male:female: } & \multicolumn{3}{|c|}{$26: 16$} & \multicolumn{2}{|l|}{$1.6: 1$} & \multirow[b]{2}{*}{ Total } & \multirow[b]{2}{*}{ Percentage } \\
\hline & $A C$ & NSC & $S C$ & $I B D$ & $A I E$ & & \\
\hline No of cases & 26 & 4 & 3 & 5 & 4 & 42 & 100.0 \\
\hline Age of onset $<6 / 12$ & 18 & 3 & 1 & 3 & 3 & 28 & 66.7 \\
\hline \multicolumn{8}{|l|}{ Signs and symptoms } \\
\hline Diarrhoea & 24 & 3 & 3 & 5 & 4 & 39 & 92.8 \\
\hline Rectal bleeding & 20 & 4 & 1 & 5 & 1 & 31 & 73.8 \\
\hline Weight loss & 18 & 2 & 3 & 4 & 3 & 30 & 71.4 \\
\hline Abdominal pain & 13 & 2 & 0 & 2 & 0 & 17 & 40.5 \\
\hline Anorexia & 9 & 2 & 2 & 1 & 2 & 16 & 38.1 \\
\hline Recurrent infections & 6 & 1 & 3 & 3 & 1 & 14 & 33.3 \\
\hline Abdominal distention & 8 & 0 & 1 & 0 & 1 & 10 & 23.8 \\
\hline Constipation & 2 & 1 & 0 & 0 & 0 & 3 & 7.1 \\
\hline Vomiting & 10 & 1 & 1 & 1 & 1 & 14 & 33.3 \\
\hline Fever & 2 & 0 & 3 & 1 & 1 & 7 & 16.7 \\
\hline Consanguinity & 0 & 1 & 0 & 1 & 2 & 4 & 9.5 \\
\hline \multicolumn{8}{|l|}{ Family history } \\
\hline Atopy/asthma & 15 & 1 & 0 & 3 & 1 & 20 & 47.6 \\
\hline IBD & 3 & 0 & 0 & 1 & 0 & 4 & 9.5 \\
\hline Atopy in patient & 9 & 0 & 1 & 1 & 1 & 12 & 28.6 \\
\hline \multicolumn{8}{|l|}{ Feeding } \\
\hline Breast milk only & 8 & 2 & 1 & 1 & 2 & 14 & 33.3 \\
\hline Cows' milk formula & 8 & 1 & 1 & 1 & 0 & 11 & 28.6 \\
\hline Soya formula & 3 & 0 & 0 & 0 & 0 & 3 & 7.1 \\
\hline Mixed & 7 & 1 & 1 & 3 & 1 & 13 & 30.9 \\
\hline \multicolumn{8}{|l|}{ Weight } \\
\hline$<3$ rd centile & 15 & 2 & 3 & 3 & 3 & 26 & 61.9 \\
\hline \multicolumn{8}{|l|}{ Height } \\
\hline$<3$ rd centile & 8 & 1 & 3 & 2 & 1 & 15 & 35.7 \\
\hline
\end{tabular}

AC = allergic colitis; NSC = non-specific colitis; SC = severe combined immunodeficiency; IBD = inflammatory bowel disease (ulcerative colitis and Crohn's disease); AIE = autoimmune enterocolitis.

Table 2 Site of macroscopic colonic abnormality in 42 infants undergoing endoscopy. All were confirmed on histological examination to have a colitis. Total colonic examination was acheived at endoscopy in 35/42 (83\%)

\begin{tabular}{lll}
\hline & No & Percentage \\
\hline Rectosigmoid & 13 & 30.9 \\
Pancolitis & 15 & 35.7 \\
Normal & 7 & 16.7 \\
Rectum to hepatic flexure & 5 & 11.9 \\
Others & 2 & 4.8 \\
Total & 42 & 100 \\
\hline
\end{tabular}

Table 3 Histological diagnoses in 42 consecutive cases of non-infective colitis in children aged $<2$ years at presentation

\begin{tabular}{lll}
\hline & No & Percentage \\
\hline Allergic colitis & 26 & 61.9 \\
Non-specific colitis & 4 & 9.5 \\
Autoimmune enterocolitis & 4 & 9.5 \\
Ulcerative colitis & 4 & 9.5 \\
Combined immunodeficieny & 3 & 7.1 \\
Crohn's disease & 1 & 2.8 \\
Total & 42 & 100 \\
\hline
\end{tabular}

Males were more common than females (ratio 1.7 to 1 ). Diarrhoea, bloody stools, and weight loss were the most common presenting symptoms. Abdominal pain, anorexia, and vomiting occurred in $41 \%, 39 \%$, and $33 \%$ of the cases respectively (table 1). In $66 \%$ of infants the symptoms started before the age of 6 months, and the duration of the symptoms before presentation ranged from two weeks to 14 months (mean duration 3.5 months).

A personal history of atopy was present in $29 \%$ overall. This was commonest in those with allergic colitis (35\%) being found in $20 \%$ of those with specific inflammatory bowel disease and $12 \%$ of those with autoimmune related colitis.

A positive family history of atopy/asthma was found in $48 \%$ of all the cases. Over $60 \%$ of the atopic relatives were grandparents, uncles and aunts, and cousins. A quarter of the infants themselves had a personal history of atopy or asthma or both. Thirty three per cent of the cases were exclusively fed on breast milk at the onset of the symptoms and another $31 \%$ were on breast and artificial milk. Recurrent upper respiratory infections were recorded in $33 \%$ of the cases.

Sixty two per cent of the cases had a weight less than the third centile for age and sex at presentation, and $36 \%$ a height less than the third centile.

All infants underwent colonoscopy and a total colonoscopic examination was achieved in $83 \%$ (35/42). Table 2 shows that during the endoscopic examination, macroscopic abnormalities of the intestine were evident in $83 \%$ of the patients. A pancolitis was found in $36 \%$ and inflammatory changes confined to the rectosigmoid $31 \%$. The rectum was macroscopically abnormal in $78 \%$ of cases. The endoscopy was macroscopically normal in $17 \%$ of the cases, and all of these had allergic colitis on histology.

Allergic colitis accounted for $62 \%$ of cases of colitis in the infants, while non-specific colitis, autoimmune enteropathy, and ulcerative colitis each accounted for $10 \%$ of the cases. Crohn's colitis was seen in only one male infant who was 18 months old (table 3 ).

Anaemia (haemoglobin $<105 \mathrm{~g} / \mathrm{l}$ ) was observed in $36 \%$ of the cases at presentation, with a mean haemoglobin concentration of $98 \mathrm{~g} / \mathrm{l}$. Thrombocytosis, increased erythrocyte sedimentation rate, and low albumin concentrations were observed in $56 \%, 49 \%$, and $55 \%$ respectively, and eosinophilia in six cases $(14 \%)$ (table 4). The nitroblue tetrazolium test and skin prick tests were normal in all the infants.

The $\mathrm{T}$ cell lymphocyte subset population showed a low CD3 and CD4 in two thirds of those with severe combined immunodeficiency (SCID) and three quarters of those with 
Table 4 Laboratory findings at presentation in 42 infants with histologically proved colitis

\begin{tabular}{lll}
\hline & No (total) & Percentage \\
\hline Anaemia $(\mathrm{Hb}<105 \mathrm{~g} / \mathrm{l})$ & $15(42)$ & 35.7 \\
Eosinophilia $(>800 \mathrm{abs})$ & $6(42)$ & 14.3 \\
Thrombocytosis $\left(>4 \times 10^{11}\right)$ & $23(41)$ & 56.1 \\
Raised ESR & $18(37)$ & 48.6 \\
Albumin $(<35 \mathrm{~g} / \mathrm{l})$ & $23(42)$ & 54.8 \\
NBT test normal & $12(12)$ & 100 \\
RAST negative & $32(32)$ & 100 \\
Positive autoantibodies & $2(26)$ & 7.7 \\
Smooth muscles & $3(26)$ & 11.5 \\
Gut & $0(26)$ & 0.0 \\
Others & $6(13)$ & 46.1 \\
Tymphocytes & $3(9)$ & 33.3 \\
Low CD3 and CD4 & & \\
Abnormal PHA response & $10(38)$ & 26.3 \\
Immunoglobulins & $18(38)$ & 47.3 \\
IgG $(<3.1 \mathrm{~g} / \mathrm{l})$ & $3(22)$ & 13.6 \\
IgA $(<0.3 \mathrm{~g} / \mathrm{l})$ & $16(27)$ & 59.2 \\
IgE $(>22 \mathrm{IU} / \mathrm{ml})$ & $13(27)$ & 48.1 \\
IgG $(<35 \mathrm{mg} / \mathrm{dl})$ & & \\
IgG & $(<4.8 \mathrm{mg} / \mathrm{dl})$ & \\
\hline
\end{tabular}

Others = antinuclear, mitochondrial, reticulin, and gastric parietal cell antibodies; ESR = erythrocyte sedimentation rate; $\mathrm{Hb}=$ haemoglobin; $\mathrm{PHA}=$ phytohaemagglutinin.

autoimmune enterocolitis, with a raised CD8 in two of the three patients with SCID who had graft versus host disease. An abnormal phytohaemagglutinin (PHA) response was observed in all the patients with autoimmune enterocolitis, and one third of patients with SCID. Both the $\mathrm{T}$ cell lymphocyte subsets and the PHA response were normal in those with allergic colitis and non-specific colitis. Immunoglobulin G concentrations were below the age related minima $(<3.1 \mathrm{~g} / 1)$ in $26 \%$ of the infants, and low IgA concentrations $(<0.3 \mathrm{~g} / \mathrm{l})$ were found in $47 \%$. Low $\operatorname{IgG}_{2}(<35 \mathrm{mg} / \mathrm{dl})$ and $\mathrm{IgG}_{4}$ $(<4.8 \mathrm{mg} / \mathrm{dl})$ subclasses were observed in $59 \%$ and $48 \%$ of the infants studied respectively. This was due to a high prevalence in those with allergic colitis, where $71 \%$ had low $\mathrm{IgG}_{2}$ and $50 \%$ low $\mathrm{IgG}_{4}$, and in ulcerative colitis where three quarters of the cases had low $\operatorname{IgG}_{2}$ and $\mathrm{IgG}_{4}$ (table 5).

\section{RESPONSE TO TREATMENT}

Table 6 shows that $77 \%$ of the infants with allergic colitis had remission of their symptoms and started gaining weight on dietary manipulation within the first three months of treatment, while only $20 \%$ of those with specific inflammatory bowel disease (ulcerative colitis and Crohn's disease) who were on steroids, salazopyrine, and dietary management went into remission in the first three months of treatment. Those with severe combined immunodeficiency and autoimmune enterocolitis responded to immunomodulation slowly, with only a quarter having a remission of the symptoms within six months of the start of treatment.

\section{Discussion}

This study showed that evidence of minor immunodeficiency is common in infants with non-infective colitis. In agreement with previous studies we have confirmed that in this age group the commonest cause of non-infective colitis is allergic colitis. ${ }^{15} 59111415$ Ulcerative colitis, nonspecific colitis, autoimmune enterocolitis, and severe combined immunodeficiency accounted for only approximately one third of the cases, occurring with the same frequency.

Serum $\mathrm{IgG}_{2}$ and $\mathrm{IgG}_{4}$ deficiency commonly coexisted with deficiencies of $\operatorname{IgA}$, raised IgE or both in this group of infants with colitis. ${ }^{16} 17$ These immunoglobulins have a role in health in protecting the individual against the uncontrolled absorption of whole proteins and complex antigens from the gastrointestinal lumen. Previous work has shown that the formation of immune complexes, particularly IgA specific immune complexes, may contribute to the release of goblet cell mucus onto the intestinal surface, thus preventing the penetration of antigens or the adherence of infectious agents. ${ }^{18} \mathrm{~A}$ deficiency of the serum immunoglobulins may lead to failure of antigenimmunoglobulin complex formation, resulting in intact antigen absorption and sensitisation of the individual. With re-exposure to dietary antigen, minute quantities of allergen may be absorbed and result in allergic symptoms. A vicious cycle of allergic reaction with increased allergen uptake across a disrupted mucosal surface may ensue. Uptake of non-specific intestinal antigen can in turn evoke an IgG mediated reaction which may predispose to chronic disease. ${ }^{19}$

Increased intestinal permeability, which is a genetically expressed defect that predisposes to the development of inflammatory bowel disease, has been reported. ${ }^{20}$ One of the genetic defects reported here is probably a deficiency of immunoglobulin $\mathrm{A}, \mathrm{IgG}_{2}$, and $\mathrm{IgG}_{4}$ subclasses which predisposes individuals to the absorption of whole antigens, an IgE mediated immunological response, and the release of inflammatory mediators, resulting in an enterocolitis. The inflamed intestinal epithelium allows more antigens to cross the mucosa and the vicious cycle continues.

Anaphylatoxins stimulate macrophages to release prostaglandin $\mathrm{E}_{2}$, thromboxane $\mathrm{B}_{2}$, and leukotriene $\mathrm{B}_{4}{ }^{21}$ thus initiating and maintaining the inflammatory and tissue damaging process (type 2 and 3 hypersensitivity).

$\mathrm{IgG}_{1}$ secreting plasma cells are the immunocyte class showing by far the greatest expansion

Table 5 Percentage of each group of infants with colitis with low circulating concentrations of $\operatorname{IgA}, \operatorname{Ig} G_{2}$ and $\operatorname{Ig} G_{4}$ subclasses and with abnormal $T$ cell subset counts

\begin{tabular}{|c|c|c|c|c|c|}
\hline & $A C$ & NSC & AIE & $U C$ & $S C I D$ \\
\hline \multicolumn{6}{|l|}{ Immunoglobulins } \\
\hline Low IgA & (23) $47.8 \%$ & (3) $66.6 \%$ & (4) $50.0 \%$ & (4) $50.0 \%$ & (3) $33.3 \%$ \\
\hline Low $\operatorname{IgG}_{2}$ & (14) $71.4 \%$ & (2) $100.0 \%$ & (4) $100.0 \%$ & (4) $75.0 \%$ & (2) $50.0 \%$ \\
\hline Low $\mathrm{IgG}_{4}$ & (14) $50.0 \%$ & (2) $50.0 \%$ & $\begin{array}{l}\text { (4) } 0.0 \% \\
\end{array}$ & (4) $75.0 \%$ & (2) $100.0 \%$ \\
\hline \multicolumn{6}{|l|}{ T lymphocyte } \\
\hline Low $\mathrm{CD} 3$ and $\mathrm{CD} 4$ & (3) $0.0 \%$ & - & (4) $75.0 \%$ & (2) $50.0 \%$ & (3) $66.6 \%$ \\
\hline Abnormal PHA & (3) $0.0 \%$ & - & (2) $100.0 \%$ & (1) $0.0 \%$ & (3) $66.6 \%$ \\
\hline
\end{tabular}

The figures in parentheses are the numbers of patients tested.

$\mathrm{AC}=$ allergic colitis NSC $=$ non-specific colitis AIE $=$ autoimmune enterocolitis; $\mathrm{UC}=$ ulcerative colitis; $\mathrm{SCID}=$ severe combined immunodeficiency; PHA = phytohaemagglutinin. 
Table 6 Time to clinical remission in 42 children aged $<2$ years with non-infective colitis treated as follows: allergic collitis, dietary exclusion(s) with/without sodium cromoglycate; autoimmune enterocolitis (AIE), immunosuppresion; non-specific colitis (NSC), ulcerative colitis, and Crohn's disease (IBD), immunosuppression and dietary manipulation

\begin{tabular}{lllll}
\hline & No & $<3$ months & 3-6 months & $>6$ months \\
\hline Total & 42 & $47.6 \%$ & $23.8 \%$ & $28.6 \%$ \\
Allergic & 26 & $76.9 \%$ & $15.4 \%$ & $7.7 \%$ \\
AIE & 4 & - & $25.0 \%$ & $75.0 \%$ \\
NSC & 4 & - & $75.0 \%$ & $25.0 \%$ \\
IBD & 5 & - & $20.0 \%$ & $80.0 \%$ \\
SCID & 3 & - & $33.3 \%$ & $66.6 \%$ \\
\hline
\end{tabular}

in specific inflammatory disease..$^{22}$ The upregulation of $\mathrm{IgG}_{1}$ is probably a compensatory mechanism that can occur when the other subclasses are low, as seen in these infants.

A family history of atopy is very common in infants with colitis in this and other studies.9-11 1423 These infants are prone to recurrent infections of the upper respiratory tract, which may be due to the $\operatorname{IgG}_{2}$ and $\mathrm{IgG}_{4}$ subclass deficiency ${ }^{16}$ as seen in our patients. The finding of a negative intradermal skin prick test in our patients is not unusual, since infants have a poor response to such tests. ${ }^{25}$

In this series, the $T$ cell function was abnormal in patients with severe combined immunodeficiency, autoimmune enterocolitis, and ulcerative colitis, but largely normal in those with allergic and non-specific colitis. The low CD3 and CD4 T lymphocyte subset population with a raised CD8 in those with SCID probably reflects graft versus host disease (GVHD) due to immunocompetent lymphocytes from the mother. The endoscopic and histological findings in two of these patients were in keeping with GVHD. Those with autoimmune enterocolitis had plasma cell plus lymphocytic infiltration of the lamina propia and the mucosa, with positive smooth muscle and gut autoantibodies.

A third of the infants in this study were exclusively breast fed when they developed colitis. Previous studies in infants fed cows' milk based formulas from birth have suggested that this group may be at a higher risk of developing allergic colitis. The condition is, however, described in children fed other whole protein milk formulas (soybean) and in infants fed on breast milk. ${ }^{14}{ }^{24}$ In this latter group, exclusion of cows' milk, egg, and soybean products from the maternal diet may alleviate the infant's symptoms.

The outcome of treatment with exclusion diet alone was excellent in the children in this study with allergic colitis. Infants with other causes of colitis took longer to go into remission, requiring immunosuppression. This group frequently relapsed when intercurrent infections occurred. No case of non-specific colitis went on to develop specific inflammatory bowel disease during follow up within the time course of this study.

We have shown that infants with noninfective colitis commonly have an associated minor immunodeficiency. We suggest that in allergic colitis low levels of $\operatorname{IgA}_{1} \operatorname{IgG}_{2}$, and $\mathrm{IgG}_{4}$ might impair the function of mucosal defences against macromolecular passage across the mucosal barrier, thus predisposing to an aller- gic inflammatory response and mucosal injury. In ulcerative colitis it seems more likely that the minor immunodeficiency alluded to here is a result of an underlying immunodysregulation, although the findings of specific IgE reaginic antibodies to cow's milk in as many as $30 \%$ of children with ulcerative colitis implies that loss of barrier function in these children might also predispose to allergic responses.

In this study population-as in others previously-allergic colitis was the commonest cause of non-infective colitis in infancy and this responded excellently to exclusion diet alone. A positive family and personal history of atopy was common in infants with allergic colitis and in this group the rectum was invariably affected. Macroscopic appearance at endoscopy did not discriminate between normality and allergic colitis, and for this reason mucosal biopsy is considered mandatory to make the diagnosis.

1. Chong SKF, Blackshaw BC, Morson BC, Willian Walker Smith JA. Prospective study of colitis in infancy and
early childhood. F Pediatr Gastroenterol Nutr 1986;5:352-8. 2 Buchino JJ, Suchy FJ Synder JN Batrial diarrhoea in infants and children. Perspec Pediatr Pathol 1984;8:163.

3 Whittum TS, Wolfe ML, Wachsauth IK, Orskov F, Wilson RA. Clonal relationship among Escherichia coli strains that cause haemorrhagic colitis and infantile diarrhoea. Infect Immun 1993;61:1619-29.

4 Robson WL, Leung AK, Miller-Hughes DJ. Recurrent Robson WL, Leung AK, Miller-Hughes DJ. Recurrent
haemorrhagic colitis caused by E coli 0157:H7. Pediatr Infect Dis ₹ 1993;12:699-701.

5 Odze RD, Bines J, Leichter AM, Goldman H, Antonioli DA. Allergic proctocolitis in infants: a prospective clinicopathological biopsy study. Hum Pathol 1993;24:668-74.

6 Rosekrans PCM, Meijer CJL, Van Der Wal AM, Lindeman J. Allergic proctitis, a clinical and immunopathological entity. Gut 1980;21:1071-23.

7 Booth IW, Harries JT. Inflammatory bowel disease in childhood. Gut 1984;25:188-202.

8 Hill SM, Milla PJ, Bottazo GF, Mirakian R. Autoimmune enteropathy and colitis: is there a generalised autoimmune gut disorder? Gut 1991;32:36-42.

9 Jenkins HR, Pincot JR, Soothill HF, Milla PJ, Harris JT. Food allergy: the major cause of infantile colitis. Arch Dis Child 1984;59:326-9.

10 Hill SM, Milla PJ. Colitis caused by food allergy in infants. Arch Dis Child 1990;65:132-3.

11 Milla PJ. Food allergic colitis in infancy. In: Dobbing J, ed. Food intolerance. London: Balliere Tindall, 1987:101-7.

12 Hoppen T, Keller KM, Stolte M, Rister M. Clostridium difficile in early childhood ulcerative pancolitis. Monatschr Kinderheild 1993; 141:132-3.

13 Gryboski JD. Ulcerative colitis in children 10 years and younger. F Pediatr Gastroenterol Nutr 1993;17:24-31.

14 Gryboski JD. Gastrointestinal milk allergy in infants. Pediatrics 1967;40:354-60.

15 Sanderson IR. Unusual colitides. Bailliere's Clin Gastroenterol 1994;8:181-96.

16 Heiner DC. Significance of immunoglobulin G subclasses. Am f Med 1984;76:1-6.

17 Oxelius VA. Immunoglobulin G subclasses and human disease. Am f Med 1984;76:7-18.

18 Walker WA, Bloch KJ. Intestinal uptake of macromolecules: in vitro and in vivo studies. Ann NY Acad Sci 1983;30:593602 .

19 Walker WA. Mechanism of antigen handling by the gut. Clin Immun Allergy 1982;2:248-51.

20 Hollander D, Vadhein CM, Bretholtz E, Peterson GM, Delahunty TJ, Retter JI. Intestinal permeability in patients with Crohn's disease and the relatives. A possible aetiologic factor. Ann Intern Med 1986;105:883-5.

21 Brandtzaeg P, Haltensen TS, Kett K, et al. Immunobiology and immunopathology of human gut mucosa: humoral immunity and intraepithelial lymphocytes. Gastroenterology 1989;97:1562-84

22 Scott Mg, Nahm MH, Maeke K, Nash GS, Bertovitch MJ, MacDermott RP. Spontaneous secretion of IgG subclasses by intestinal mononuclear cells: differences between ulcerative colitis, Crohn's disease and controls. Clin Exp Immunol 1986;66:209-15.

23 Gilat T, Hacohen D, Lilos P, Langman MJ. Chilhood factors in ulcerative colitis and Crohn's disease. An international cooperative study. Scand 7 Gastroenterol 1984;22:1009-24.

24 Powell GK. Milk and soy induced enterocolitis of infancy. $\mathcal{f}$ Pediatr 1978;93:553-61.

25 David TJ. Unhelpful recent development in the diagnosis and treatment of allergy and food intolerance in children. In: Dobbing J, ed. Food intolerance. London: Balliere Tindall, 1987:185-214. 